\title{
Towards a Theory of Things: Reversal Theory and Design
}

\author{
Michael J. Apter \\ Apter Research, LLC
}

\begin{abstract}
The aim of this paper is to initiate the development of a "theory of things." This would be a theory of the psychological impact that objects of various kinds have on people, especially on their motivation and emotions, and would call on reversal theory for its foundations. On the applied side, it would be relevant to designers looking for a systematic way of developing their creative work. The present paper reviews some ingredients drawn from reversal theory that we might expect in such a theory of things. These include contingent reversal, coming in the form of the innate meanings that have been studied by ethologists, formal aspects of objects such as color and shape, and the cultural and individual meaning that humans learn to associate with different kinds of objects. All of these appear to be able to act as reversal agents, and can be made use of in "the eight rooms" technique for inducing reversals. Other reversal theory concepts can also be brought to bear on the development of a theory of things, including the concepts of protective frame, and cognitive synergy.
\end{abstract}

Keywords: cognitive synergy, design, parapathic emotion, protective frame, reversal theory, thing theory

In the modern world we are surrounded by objects of various kinds, including objects that are specifically designed to have a psychological effect such as advertisements, traffic signals, expensive jewelry, monuments, guns, iPads, and so on. Most of us spend much of our time in our urban daily lives interacting with objects, especially man-designed and man-made objects. Much of our subjective life world consists of the experience of objects separated and spread around in space. More specifically, it could be said that many of us live much of our lives interacting with "objects in rooms." Perhaps it is a little strange that we do not have a psychology of things and places. What is needed is what we might call, perhaps a little playfully, a "theory of things." This would be a theory not of the physical properties of things but rather of the psychological impact that things of all kinds have on people, especially on their motivations and emotions. This would involve not only aesthetics but also the various other psychological needs addressed by things at different times and in different ways.

"Thing" here will be taken to include not only what we normally think of as things - not only objects and rooms - but also cars, houses, clothes, furniture, trees, flowers and so on. There are no doubt huge grey areas here in deciding what is a thing, such as whether a cloud is to count as a thing, or a meal is to count, or a country. But deciding these in particu-

Correspondence concerning this article should be addressed to Michael J. Apter, Apter Research LLC, 530 Audubon Drive, Ruston, LA 71270, USA E-mail: mjapter@aol.com lar areas is not essential to the general ideas to be presented here.

As a theory of the structure of experience of everyday life, reversal theory seems to be well positioned to provide insights that would help in the development of such a theory. Things can obviously have many different psychological effects at the level of motivation and emotion. These include: rewarding/punishing, promising/warning, helping (tools)/hindering (barriers), arousing/relaxing, inducing reversals/ preventing reversals. The main focus in the present paper will be on the power of things to change motivational states and consequent emotions. In this respect we shall be going beyond the obvious. Thus a car is a thing that allows people to travel, but our interest in this paper will be in the satisfactions and dissatisfactions that people have while using this object. Thus they might, at a given moment while driving, experience excitement, at another moment pride, and at yet another moment anger.

The development of a theory of things could provide a contribution to the psychology of design, leading towards a systematic guide for designers in their creative work and be a contribution to "motivational design" (Keller, 1988). At the moment, designers have little in the way of systematic psychological theory to guide them, but must rely largely on their intuitions and experiences. It would also extend our understanding of contingent reversals and thus be a significant addition to reversal theory. Note that we are not dealing primarily with the aesthetics of things (although this will come into the picture), but rather about their motivational and emotional impact, which may derive from functional as well as aesthetic considerations. 
The aim of this paper is not to provide a complete theory of things - this would be much too large a task - but rather to suggest some key elements of what might eventually become part of a complete theory, deriving these from reversal theory.

We shall begin with the idea that things can have various kinds of motivational and emotional impact, outlining four different patterns of impact. Then we shall look more specifically at the idea of contingent reversal, looking at both innate and learned cues to such reversal, followed by the description of a way of inducing states that makes use of contingent reversal. This will be followed by an exploration of the reversal theory concepts of protective frames and cognitive synergies and will show their relevance to a theory of things. Some issues arising from all of this will be noted in a final section. Taken as a whole, we shall be looking at "things" from various perspectives afforded by reversal theory, and applying reversal theory concepts.

Incidentally, the title "A theory of things" is preferred here to "a theory of objects" because the latter might cause confusion with "object relations theory" which has a very different, psychoanalytic, perspective. The name 'thing theory' has also been used previously, to denote the place of things in literature (Brown , 2001a, 2004). The present writer assumes that this usage is whimsical, but one can never tell with postmodern cultural theorists. Topics of interest would be, for example, the part that the handkerchief plays in Othello, the whale in Moby Dick, the lighthouse in Virginia Woolf's famous novel, and so on. Confusion is not likely to arise between the two appellations of 'thing theory' since they are directed to very different issues.

\section{Impact types}

In the reversal theory model, when a reversal occurs, this reversal precedes, or is simultaneous with, any emotion that might be experienced in the new motivational state. The state is a precondition for the emotion. It would for example not be consistent with the theory to say that something induces anxiety and the anxiety brings about the telic state. What a reversal theory interpretation would say in this case is that something induces the telic state, and as a consequence, if there is also high arousal, anxiety is felt. This is a point that has sometimes been misunderstood. Conceptually, it is the motivational state that changes when a reversal occurs and then this state has emotional and other effects including the experience of particular emotions. This has been implicit in previous reversal theory discussions, especially of arousal and emotion, and has been made explicit in many places (e.g. Apter, 1982a, p.85; 2001, pages 42-43, proposals 3 and 4 under the 'emotions' heading.) In this model, the motivational state that is active, and the level of felt arousal or level of felt transactional outcome (i.e. the feeling of gaining or losing), are independent variables, while hedonic tone and emotion are dependent variables. This is elucidated in the so-called 'butterfly curves' for the somatic states (that are related to felt arousal) and the transactional states (that are related to felt transactional outcome from losing to gaining).

Given this, there are four alternative kinds of effect - let us call them impact types - that a thing can produce in a person at the motivational/emotional level. All four types are of interest from the point of view both of a theory of things and more generally of reversal theory, although reversal theory is particularly interested in types 3 and 4 listed below, since these involve reversals.

1. The thing causes emotional change without a reversal occurring (i.e. it changes only level of felt arousal and/or felt transactional outcome). Here are some examples:

a. An individual already in the telic state hears news that increases his arousal, thus increasing anxiety.

b. Someone already in the self-oriented sympathy state combination is given a gift. This does not change the state combination, but changes the emotion to greater gratitude.

c. Someone at a football match is in the mastery and playful states, and then their team scores a goal. This does not change the already existing state combination, but changes the emotion to greater pride and greater excitement.

d. An individual in the telic state is anxious because he has lost something important, but when he finds it he becomes relaxed.

2. The thing causes changes in which of the motivational states are focal from among the ongoing active states, but without a reversal occurring

a. At a concert the music changes from exciting and tense (paratelic) to tender and loving (sympathy).

b. Food at a restaurant is too salty, leading to a focus on anger (negativism) rather than enjoyment (paratelic).

c. The athlete turns from worrying about what will happen if he loses (telic), to concentrating on what he has to do to win (mastery).

3. Exposure to the thing does bring about a reversal, but does not change the level of felt arousal or felt transactional outcome.

a. Someone sees an advertisement for car insurance, which causes reversal to the telic state, but no change of arousal level.

b. Someone receives an official-looking letter, which causes reversal to the telic state while opening it, but no change to arousal level .

c. Someone sees his cell phone lying on his desk and decides to phone a friend. This involves a reversal from the mastery to the sympathy state occasioned by the sight of the phone. But it does not at this point involve a change in felt transactional outcome. 
4. The thing brings about a reversal and changes to arousal level or felt transactional outcome.

a. An avoided car accident causes a reversal from paratelic to telic and also raises arousal levels so that anxiety is felt.

b. Someone hears a patriotic march being played by a marching band, and this both induces the mastery state and satisfies it with feelings of increased pride.

c. Someone driving is passed by an ambulance with its siren going, which induces the telic state and also increases arousal, causing anxiety.

d. Someone hears a joke, which induces the paratelic state and also provides a pleasant spike of excitement.

\section{Contingent reversals}

Let us look next at the reversal theory concept of 'contingent reversal.' By this is meant simply a reversal brought about by some environmental event or situation (Apter, 2001, p.46). This event or situation will in many cases consist of the actions or words or expressions of other people. In this paper we shall focus instead on reversals brought about by physical situations, including places and objects.

This idea of external objects and events (both human and inanimate) being agents of reversal is one of the basic concepts of reversal theory. Contingent reversals contrast with reversal brought about by frustration and reversal brought about by satiation, the two other main suggested categories of reversal agent. These three agents of reversal go back to the very first publication on reversal theory (Smith and Apter, 1975) and are still used as explanatory concepts in the theory. In particular, contingent reversal contrasts with satiation which is postulated to be an entirely internal process having nothing to do with the environment. Different types of contingent reversal have been discussed by Desselles \& Apter (2013). In the following, we shall look at aspects of things that may act as cues to prompt reversal.

\section{Instinctive meanings}

There appear to be many configurations of stimuli that automatically release instinctive behavior patterns. Ethologists like Lorenz (1966) and Tinbergen (1951) studied these in animals of various species, typically in their natural habitats. An obvious example would be the stimulus of a running mouse releasing predatory behavior in a cat. Later, the study of such 'releasers' was extended to humans by researchers like Desmond Morris (1967). It would seem reasonable to assume that different motivational states might be released by instinctively recognized events. For example, extending Morris (1977), there seems to be an innate fear of snakes in human beings, and so it would seem that the sight of a snake would induce the telic state as a precondition for the fear. Large eyes induce maternal behavior in women, and this means that they would induce the sympathy state as a precursor to the feelings of caring. Naked female breasts typically induce the paratelic state in men, which allows the stimulation to be experienced as excitement. In other words, reversals may be bound up with instinctive reactions to things of many kinds, and underlie the different emotions that these instincts call up. We may suppose that these are typically of the impact type 4 (above), calling forth both reversals on the one hand and change in arousal or in transactional outcome on the other.

Note that these things that evoke states, since they are concrete, can be taken, and used in art and other kinds of messaging, as symbols of different states, even where they do not actually evoke the state, e.g. a stylized tiger to represent the mastery state on football team jerseys, or an apple to represent the sinfulness of the rebellious state in medieval paintings of the Garden of Eden. The interesting question of when and how a releaser can be converted into a symbol, and a symbol into a releaser, will be a matter for future research.

\section{Color}

As well as meaningful objects, like snakes and eyes, rather more abstract formal qualities appear also to have innate reversal power (Fontana, 1984, 1991). These include smell, temperature, size, and so on (Augustin, 2009). But this reversal power would appear to be particularly true of color and shape, and we shall look at these two qualities now.

There is evidence, for example (reviewed by Alter, 2013), that exposure to the color pink has a pacifying effect on people. He cites an experiment by Schauss (1979) who measured degree of physical resistance to pressure on participants' raised arms when they had been exposed to either deep blue or bright pink. The response of those exposed to pink was significantly weaker than that of those subjected to blue. In another study, this one at the U.S. Naval clinic in Washington, detainees in a pink holding cell were reported to be less aggressive than others who were not kept in this color cell. Nine other papers are cited by Schauss, generally supporting this theme, which was taken up by athletes and others. For instance, Colorado State University and the University of Iowa, painted visitor's changing rooms pink. None of this research or application measured motivational states as such, but the distinct impression is that pink tends to put those exposed to it into the sympathy state which is of course less competitive and aggressive than the opposing mastery state. This would be consistent with the present author's observation in workshops that pink is a color which is strongly associated with the sympathy state (see section on the Eight Rooms, below). It also appears to lower arousal, thus having the combined effect identified in impact type 4 above.

Another color that has been studied is black. Frank \& Gilovich, (1988) analysed the penalty records of black- 
uniformed National Hockey League teams and National Football League teams, and found that they attracted many more penalties than teams wearing other colors. This could be due either to referees being more likely to see the same actions as fouls when committed by players in black uniforms, or that players wearing these uniforms were more likely to actually behave in a rebellious rule-breaking way. Either way, this is consistent with the present author's workshop observations of peoples' tendency to associate black with transgression and moral impurity (and white with conformity and purity).

In a study of red by Hill \& Barton (2005), four Olympic combat sports were observed: wrestling, free style wrestling, tae kwon do, and boxing. They found that the athlete wearing red beats the athlete wearing blue beyond chance levels. (Note that blue and red uniforms are assigned randomly in these sports.) In an analysis of English professional soccer clubs over a 55 year period, Attrill, Gresty, Hill \& Barton (2008) found that red-shirted teams have been champions more often than expected on the basis of the proportion of clubs playing in red. On this basis, red would appear to be a mastery color, although why it would encourage the mastery state in those wearing it, rather than those seeing it on their opponents, remains something of a mystery.

We do have to be careful in interpreting these results on color, since the effect may be to change an emotion within a state rather than to change the state. This latter eventuality would be an example of the first of the four kinds of impact described earlier. Walters, Apter \& Svebak (1982) found, as with previous studies they cite, that people rated hot colors like red as arousing and cool colors like blue as de-arousing. This implied to them that cool colors would be preferred by people in telic state of mind (because low arousal is felt as pleasant relaxation in this state) and hot colors would be preferred by people in the paratelic state of mind (because in this state high arousal is felt as pleasant excitement). This is what they did indeed find when they asked people at regular intervals during the working day to choose which color they preferred from a color spectrum and also administered a state measure that indicated whether they were in the telic or paratelic state of mind at that moment. The state measure indicated that people were indeed in the telic state when they chose cool colors and in the paratelic state when they chose hot colors. But the colors were presumably chosen to change the pleasantness of the emotion within a continuing state (impact type 1); if they also brought about reversals then this would have made them inappropriate as a way of identifying state, since they would be changing what they were designed to measure.

\section{Shape}

As we know from the classic work of the Gestaltists, when we recognize an object, we do so largely through its shape, although many other factors may come into play (Koffka, 1935). Are there some basic shapes that represent different motivational states? Fontana $(1985,1991)$ believed that there are, starting from the observation well-known to designers, that there are some basic shapes that underlie all the particular shapes that we find in the world around us. Three of these have been labeled essential forms (Govinda, 1977) and can be listed as follows:

Cube: This touches another flat surface with a whole surface.

Cylinder: This touches another flat surface with a line.

Sphere: This touches another flat surface with a point.

Of these three, the cube is the most immoveable, the sphere the most moveable, and the cylinder is between the two in moveability. Fontana argued that the cube, as the most immoveable, could be said to represent fixity of purpose, while the sphere as the most moveable represents flexibility. This implies that the square represents the telic, and the sphere the paratelic, states. In support of this, Fontana has pointed out that serious things tend to be rectilinear: bureaucratic forms, tombstones, courtroom layout, cheques, and so on. In contrast, many paratelic things involve roundness, especially in the form of balls: football, baseball, soccer, etc. Indeed, games tend to be based on something round. Developing this theme, Fontana further points out that various phrases in English seem to support the idea that rectangularity is associated with the telic state. Here are some phrases from Fontana, with others added: "standing four square," he's a square," "a square meal," "display rectitude," "square up to each other," "fight your corner," "going straight," "the company board." Likewise the spherical shape relates to the paratelic state: "play around," "mess around," "fool around," "a round in a pub," "having a ball," "going to a Ball," "going to a circus," "a round in boxing."

What is not clear, and requires further research, is whether these shapes simply symbolize the telic and paratelic states or have the power to induce them. McClelland (1961) argued that shapes can indeed invoke motives, and used this idea in his controversial analysis of pre-Columbian cultures in terms of the patterns that they used on their pottery.

\section{Learned cues to reversal}

Often when we are switched into a different motivational state by an object, it is because the object is associated with something in our memory that is powerful in inducing that state when we bring it to mind. In other words, certain states may be conditioned to certain objects. It would seem that given cultures associate certain things with certain objects and that these objects consistently induce motivational states within that culture: the stars-and-stripes flag inducing the mastery state, Coca-cola inducing the playful state, traf- 
fic lights inducing the conforming state, and so on. (This raises interesting questions about material culture. For example, is mastery becoming more prevalent in our culture because of digitization and commoditization? Is the otheroriented state becoming more prevalent because of the time we spend watching television and identifying with people on the screen?)

But things may be more personal and individual. Perhaps wine is, for a given person, conditioned to the paratelic state because she drinks some every evening to relax after work, or a particular make of car is conditioned to the mastery state because he remembers how powerful he used to feel when he used to drive one, or a particular tie is conditioned to the sympathy state because he was wearing it when his daughter was born.

Such personal conditioning sometimes leads to objects that are pathological in their effects. For example, sexual fetish objects in men - like high heel shoes, or lipstick, or fishnet stockings - induce the paratelic state, and with it the enjoyment of sexual feelings. At the other extreme, phobias can be learned, like the fear of insects or needles, and these objects therefore automatically induce the telic state. In such cases, we typically see the object having an impact both on motivational state and arousal level (thus constituting the impact type 4 defined above).

The upside of conditioning (Desselles \& Apter, 2013) is that it is possible to self-condition by deliberately associating chosen objects, images or thoughts with situations in which one regularly experiences a given state - so that this state can be called up at suitable moments by bringing the associated object to attention. How far this is in fact possible will only be known with further research.

\section{The Eight Rooms Technique}

A practical technique based on the idea that surroundings and objects can contingently influence motivational state, has already been used in reversal theory workshops over many years (Reese \& Apter, 2011). This is known as the Eight Rooms Technique. The aim is to help people to induce particular motivational states in themselves as-and-when they judge that they need them, by imagining different 'things.' It can result in any of the impact types described earlier, but it is used particularly to obtain the third and fourth types, which involve reversal.

Participants are asked to think of a corridor with four rooms facing each other on each side. One room is labeled "Serious," the room opposite is labeled "Playful," and so on for all the states down the corridor. They are asked to furnish each of these eight rooms, in their imagination, with things that they strongly associate with the state indicated on the door of the room. This will be furniture, but also objects of any kind - souvenirs, photos, etc. They are also asked to think of suitable colors, music, food, textures and perfume, for each room. They are then asked to memorize what they have placed in each room.

Back in their day-to-day lives, when they judge that they need to experience the world through a particular motivational state, in their imagination they enter the room associated with that state, where, hopefully, they will be overwhelmed with cues to the desired state. Here are some typical things that people have put in these imaginary rooms, or included as features of these rooms:

Serious: Large desk, bookcases, quiet music, soft colors, dark curtains

Playful: A pack of beer, a television set, loud music, bright colors, a couch

Conformity: White walls and furniture, everything clean, things lined in rows

Rebellious: Black walls, graffiti, leather clothes, noise, drugs, general untidiness

Mastery: Trophies, guns, stuffed animals, diplomas, sports equipment

Sympathy: Soft furnishings, pastel colors especially pink, pets, flowers, family photos

Self-oriented: Locked doors, mirrors, favorite books, chocolates, 'me-wall,' a bath

Other-oriented: Open door, tea on the boil, family photos, comfortable chairs

This technique is very much thing-oriented, but the things are virtual and imagined. In some cases the associations have been learned as part of our culture, in others, apparently, the objects relate to instinctive patterns, like colors, that release motivational states.

\section{Things as protective frames}

One feature of certain special things that has been much discussed in the reversal theory literature (e.g. Apter, 2007b) is the protective frame. This kind of "thing" converts the telic into the paratelic state and as a result, where arousal is high, anxiety into excitement (e.g. see evidence in Apter \& Batler, 1997, Legrand and Apter, 2004, Kerr, Kawaguchi, Oiwa, Terayama \& Zukawa, 2000). This frame comes in many forms, including practice, experience, confidence, and reliance on others. But the form that is particularly interesting from the point of view of design is the physical embodiment of protection. Sometime this looks nothing like a frame, but it still has a protective function (e.g. a rope to a climber, a condom to a lover, an antiseptic soap to a surgeon). At other times it clearly physically surrounds the risk-taker. We see this particularly where some physical space is set aside for play, and a physical protective frame demarcates an area where harm cannot come. For example: a football stadium, a tennis court, a playground, a swimming pool, a theatre, a cinema, a casino. 
Here play space is cut off from the world of serious consequences, especially from trauma and harm. In other words, the enclosed physical space turns one towards playful action, action for its own sake, within that space.

One of the interesting things about the paratelic state, and the protective frame that defines this state, is that all emotions when they are experienced with some intensity in this state become enjoyable - even supposedly unpleasant emotions like anger, horror, or grief - because they become a kind of excitement. These hedonically inverted emotions are described as 'parapathic' or 'paradoxical' emotions. A general theory of things must obviously take these into account if it is to be in any way complete, and it provides a great resource for designers. Fokkinga \& Desmet (2013) have devised intriguing and creative methods for inducing, by design, a range of different parapathic emotions, including combinations of emotions. Parapathic emotions may be useful tools in dealing with emotional problems: Ruijs, Desmet, \& Sonneveld, (2012) have shown in children how the anxiety of being in hospital can be converted into a kind of parapathic adventure by the use of certain playful materials that they have developed.

\section{Things as cognitive synergies}

There is another potential feature of things that would need to be taken into account in any full theory of things, and this is their apparent ability in some cases to escape the normal laws of logic. The result is referred to in reversal theory as cognitive synergy (Apter, 1982a, b, 1984, Coulson, 2001) and can be defined as the perception of an entity as having two or more incompatible meanings or characteristics. This conjunction is not logically possible since something cannot at the same time both have a certain characteristic, like big, and a mutually exclusive characteristic, like small. This requirement is one of the bases of traditional logic, and goes back to Aristotle's law of the Excluded Middle, which says that A must be either B or not-B, but cannot be both. However, while not logically possible, such self-contradictions are psychologically possible. The "trick" of cognitive synergy is that something purports, or appears, to be something that it is not. In this way mutually exclusive ideas are brought together in relation to the very same identity, even if one of these ideas is not strictly veridical. Here are some obvious everyday examples: a landscape painting looks like a landscape but clearly is not, a child's doll's house looks like a real house but isn't, a military video game may feel as if it involves real combat but does not, a cuckoo clock does not have a real cuckoo, although it has something that vaguely looks and sounds like one.

Reversal theory postulates that cognitive synergies are enjoyed in the paratelic state, because of the increased arousal that they can produce, but generally disliked in the telic state unless they can be used for some significant purpose. Either way round they produce an effect which is more intense than either of the meanings could have produced alone, and it is for this reason that they are called "synergic."

Designers in various fields, especially artists, make great use of synergies in creating designs that are interesting and attractive. Here are some categories of synergy, together with examples:

\section{Depiction}

The very act of visually depicting something is synergic. What is represented, e.g. a landscape, and what 'does the representing,' i.e., a canvas with paint, are of the very same thing. The painting purports to be something other than itself. The power of pure depiction has been known since the beginnings of recorded history, as we see from cave paintings dating back 45,000 years. There is clearly a kind of magic in this seeming escape from logic, a magic which is called on down to the present time, when any blank space on a building or wall becomes covered in graffiti. However, in particular cases depiction can become a kind of dead metaphor due to it being used too widely. Thus a landscape painting, to give an example already mentioned, has only minimal synergic effect in our modern world, unless there is some way of drawing attention to it as an object rather than an apparent scene.

\section{Signifier/signified synergy}

This is a development of the depiction form of synergy into something more complicated and paradoxical. If in depiction, as just defined, we see something depicting something other than itself, in signifier/signified synergy we see something depicting itself. For example, occasional paintings include a painting within themselves, such as a painter painting a painting, and in the process they show what the painter is painting. But what is the status of this painting of a painting, of this patch of paint on canvas? Given that there is only one thing, the patch of paint, is this a painting or a painting of a painting. If the latter, where is the painting that it is a painting of? We have here something like the famous 'liar paradox' which, referring to itself, says "this statement is false."

\section{Ambiguity}

When something is ambiguous it means that different interpretations are possible, and that in this respect synergy is, as it were, built in to the object. A famous example would be Mona Lisa's enigmatic smile. Coming across some mechanical device whose function is unknown to us can produce a pleasant feeling of puzzlement. Ambiguity, by definition, evokes alternative interpretations in us and is therefore unavoidably synergic. 


\section{Metaphor}

In metaphor (Apter, 1982b), two different mutuallyexclusive entities are held together by a common characteristic, like a person and a summer's day in Shakespeare's famous sonnet. Metaphors can be built into an object in three different ways. Firstly, a connection is made between different things in the same larger thing. Thus in a Lego set construction, two things are held together visually by being made from the same plastic units, for instance a man and a car. The little man and the car are both like and unlike each other. Secondly, a thing can be made in such a way that it suggests a different thing, beyond itself - for example a pen, to a Freudian, might suggest a penis. Thirdly, there can be a kind of intertexuality: thus a car design can make a knowing allusion to an earlier, 1930s gangster style of car, as does the recent Chrysler PT Cruiser.

It has been claimed in reversal theory that cognitive synergies are enjoyed in the paratelic state, because they cause some degree of increased arousal, and are not liked in the telic state for the same reason. The key issue for future research is: do cognitive synergies also induce states, in other words do they go beyond providing pleasure or displeasure within a given state? The example of humor - a special kind of synergy (Apter, 1982, Apter \& Desselles, 2013) - seems to imply that they can act as reversal agents - and they have been used for this purpose in some previous research (Svebak $\&$ Apter, 1987). But the role of synergy as a reversal agent both in general and in the form of things, must be a question for future investigations.

It can be noted that not only synergies, but objects displaying visual complexities of any kind, including contrasts and surprises, can also be pleasurable in the paratelic state. This impact type 1 idea was pioneered in architecture by Michael Venturi (1966) and has been very influential in contemporary architecture (see discussion of Venturi in Apter, 1982).

\section{Further considerations}

There are three fairly obvious ways in which the picture presented here might need to be supplemented to give a more complete, if still preliminary, account - and perhaps avoid some wrong impressions.

\section{Ownership}

It is possible that ownership of an object has psychological effects that are greater than, or at least different from, those of an object that is not owned, or that belongs to someone else. Csikszentmihalyi \& Rochberg-Holton (1981), in their survey of peoples' attitudes to the objects in their homes, identified three broad effects of owned objects. The first is that it demonstrated the owner's power in some way, for example by being able to show off antiques, or an expensive car, to friends and neighbors. From the reversal theory point of view we can see this as involving the mastery state. Secondly, ownership over time helped people to feel the continuity of their selves over time. This probably represented the self-oriented state. Thirdly, ownership gave evidence of the owner's place in the social network - where they fit in to things, as represented by their tastes, interests, and sensitivity to fashion - thus involving the conforming state. It is possible to speculate that the other five reversal theory states might also be satisfied through ownership. The telic state finds a purpose in life through long-term acquisition, as in house-ownership. The paratelic state finds immediate enjoyment through ownership hobbies, such as collecting baseball cards. The negativistic state can experience the pleasure of having freedom of choice that can only come through ownership. The sympathy state can indulge self or other through ownership of luxuries. The other-oriented state can gain pleasure through transfer of ownership, e.g a donation to a charitable cause.

\section{Context}

A person's response to an object is often really a response to an object-plus-person, e.g. a gift plus gift-giver, an attractive dress-plus-wearer, a house plus-owner, and so on. In such circumstances, it may be difficult or even impossible to assess just how much of a person's response, which might be a reversal, is due to the person who is associated with the thing in question, and what they are doing, and how much to the thing itself. Likewise, often the response to an object is really the response to an object in a particular environment, and would be different if the object were to be in another environment. Response to a refrigerator in a kitchen would be likely to be different from the same refrigerator standing in a garden. If anthropological structuralists like Levi-Strauss (1966) are right, things are always likely to be part of what we might call "thing structures," and cannot be experienced as isolated from them. In dealing with things, we need to think holistically. We also need to see things from different angles. As Norman has argued in his user-centered approach to design (Norman, 2002,2005) designers need to see the world through the eyes of the consumer.

\section{State and thing: competing realities}

This paper may have given a rather passive view of our relationship to things, which will need rectifying. After all, we do not just get pushed around by objects. We design objects, we construct objects, we choose objects, we arrange objects, we combine objects, we visit objects, we modify objects, we put objects to one side, and we even destroy objects. If objects influence us it is often because we have chosen that they should do so (although accidental situations may also of course occur). Indeed, in this deliberate way we can use things as psychological tools to induce or 
sustain reversals in ourselves and others, thus bringing motivational processes under our own control, as in the eight rooms technique. At the very least, we can impose meaning on the objects, as demonstrated through projective tests like the Rorschach in which we find meaning in shapes and colors that are essentially meaningless. This means that we can construe objects in ways that are congruent with our ongoing motivational states, thus helping to maintain those states. For example, at one time we may see a wall as a protective frame, thus supporting the paratelic state, at another time as a constraint (thus maintaining the negativistic state) and at yet another time as a demarcation of personal territory (thus holding on to the self-oriented frame). This mitigates the power of things as reversal agents, since, to cause a reversal, they have to overcome the way that the ongoing states are seeing the world in order to replace them by a different way. In this respect we can see things on the one hand and motivational states on the other, as struggling for ascendancy. At any one time we can ask: Will the ongoing motivational state assimilate the object into its continuing world view, or will the object overwhelm the ongoing state with the physicality of its concrete presence and be able to induce a different way of seeing things through a reversal?

\section{Conclusion}

Understanding the motivational effects of the physical world of cars, streets, shops, offices, and the like, should be an unavoidable part of reversal theory since they play such a large part in our lives, especially if we live in urban environments. A 'theory of things' takes us very close to the experience of everyday life as it is actually lived in our objectdominated culture. Such a thing theory should also help us to manipulate motivational states in useful and practical ways for a variety of purposes in the clinic, the classroom, the sports field, the workplace - and the psychology laboratory. It is to be hoped that it can also particularly help to inform the work of designers of all kinds and help them to understand more deeply, and through such understanding amplify more fully, their natural creativity.

\section{References}

Alter, A. (2013) Drunk tank pink: And other unexpected forces that shape how we think, feel, and behave. New York: Penguin Press.

Apter, M.J. (1982a) The experience of motivation: The theory of psychological reversals. London and New York: Academic Press.

Apter, M.J. (1982b) Metaphor as synergy. In, D.S. Miall, (ed) Metaphor: Problems and perspectives (pp.55-70). Sussex: Harvester Press.

Apter, M.J. (1984) Reversal theory, cognitive synergy, and the arts. In, Crozier, W.R. \& Chapman, A.J. (eds.) Cogni- tive processes in the perception of art (pp.411-426). Amsterdam: North Holland.

Apter, M.J. (ed.) (2001) Motivational styles in everyday life: A guide to reversal theory. Washington, DC: American Psychological Association.

Apter, M.J. (2007a) Reversal theory: The dynamics of motivation, emotion and personality. Oxford: Oneworld Publication.

Apter, M.J. (2007b) Danger: Our quest for excitement. Oxford: Oneworl d Publications.

Apter, M.J. \& Batler, R. (1997) Gratuitous risk: A study of parachuting. In, Svebak, S. \& Apter, M.J. (eds.) Stress and health: A reversal theory perspective (pp.119-129). Washington, D.C.: Taylor \& Frances.

Apter, M.J. \& Desselles, M.L. (2013) Disclosure humor and distortion humor: A reversal theory analysis. Humor: International Journal of Humor Studies 25 (4), 417-435.

Attrill, M.J., Gresty, K.A. Hill, R.A. \& Barton, R.A. (2008) Red shirt colour is associated with long-term team success in English football. Journal of Sports Science, 26 (6) 57782.

Augustin, S. (2009) Place advantage: Applied psychology for interior architecture. New York: Wiley.

Brown, B. (2001) Things. Critical Enquiry, 28, 1, 1-22.

Brown, B. (ed.) (2004) Things. Chicago: University of Chicago Press.

Coulson, A.S. (2001) Cognitive synergy. In Apter, M.J. (ed.), Motivational styles in everyday life: A guide to reversal theory. Washington, DC: American Psychological Association.

Csikszentmihalyi, M.\& Rochberg-Holton, E. (1981) The meaning of things: Domestic symbols and the self, New York: Cambridge University Press.

Desselles, M.L. \& Apter, M.J. (2013) Manipulating motivational states: A review. Journal of Motivation, Emotion, and Personality, 1, 44-49.

Fontana, D. (1985) Educating for creativity. In, Apter, M.J., Fontana, D., \& Murgatroyd, S. Reversal theory: Applications and developments (pp. 72-88). Cardiff, UK: University College Cardiff Press.

Fontana, D. (1991) Shape, colour and symbols. In, Kerr, J.H. \& Apter, M.J. (Eds.) Adult play: A reversal theory approach (pp. 141-149). Amsterdam: Swets \& Zeitlinger.

Fokkinga, S.F. \& Desmet, P.M.A. (2013) Ten ways to design for disgust, sadness, and other enjoyments: A design approach to enrich product experiences with negative emotions. International Journal of Design, 7 (1) 19-36.

Frank, M.G. \& Gilovich, T. (1988) The dark side of self- and social-perception: Black uniforms and aggression in professional sports. Journal of Personality and Social Psychology, 54, 74-85

Keller, J.M. (1988) Motivational design. In, UC (ed.) Encyclopedia of educational media communications and tech- 
nology, (2nd edn.) (pp.406-409), Westport, CT: Greenwood Press.

Gore, N. (2004) Craft and innovation: Serious play and the direct experience of the real. Journal of Architectural Education, 58, 1, 39-44.

Govinda, A. (1977) Creative meditations and multidimensional consciousness. London: Allen and Unwin.

Hill, R.A. \& Barton, R.A. (2005) Red enhances human performance in contests. Nature, 435, 293.

Kerr, J.H., Kawaguchi, C., Oiwa, M., Terayama, Y., \& Zukawa, A. (2000) Stress, anxiety, and other emotions in Japanese modern dance performance. Pacific Journal of Psychology, 11,1, 16-33.

Koffka, K. (1935) Principles of gestalt psychology. New York: Harcourt, Brace and Company.

Legrand, F.D. \& Apter, M.J. (2004) Why do people perform thrilling activities?: A study based on reversal theory. Psychological Reports, 94, 307-313.

Levi-Strauss (1966) The savage mind. Chicago: University of Chicago Press.

Lorenz, K. (1966) On aggression. London: Methuen.

McClelland, D. (1961) The achieving society. Princeton: D.Van Nostrand.

Morris, D. (1967) The naked ape, London: Jonathan Cape.

Morris, D. (1977) Manwatching: A field guide to human behavior. St.Albans, U.K.: Triad Panther.

Norman, D.A.(2002) The design of everyday things. New York: Basic Books.
Norman, D.A. (2005) Emotional design: Why we love (or hate) everyday things. New York: Basic Books.

Reese, G. \& Apter, M.J. (2011) Thriving in the workplace: A personal development workshop. Paper presented at the 15th. International Reversal Theory Conference, Washington, D.C.

Ruijs, F., Desmet, P.M.A. , \& Sonneveld, M.H. (2012) The adventure of a hospitalization: Bringing the reversal theory to life. In, Brasset, J., McDonnell, J. \& Malpass, M. (eds) Out of control: Proceedings of the 8th International Conference on Design and Emotion, London, Saint Martins College of Art and Design.

Schauss, A.G. (1979) Tranquilizing effect of color reduced aggressive behavior and potential violence. Orthomolecular Psychiatry, 8, 218-221.

Smith, K.C.P. \& Apter, M.J. (1975) A theory of psychological reversals. Chippenham, UK: Picton Publishing.

Svebak, S. \& Apter, M.J. (1987) Laughter: An empirical test of some reversal theory hypotheses. Scandinavian Journal of Psychology, 28, 189-198.

Tinbergen, N. (1951) The study of instinct, Oxford: Oxford University Press

Venturi, R. (1966) Complexity and contradiction in architecture. New York: The Museum of Modern Art.

Walters, J., Apter, M.J., \& Svebak, S. (1982) Color preference, arousal and the theory of psychological reversals. Motivation and Emotion, 6, 3, 193-215. 